\title{
A Educação/Formação de Adultos no jogo entre o global e o local
}

\author{
Daniela Silva
}

Instituto de Educação, Universidade do Minho

\begin{abstract}
Resumen
Na aurora do novo século esboçou-se em Portugal uma nova arquitetura na promoção do direito à educação destinada aos adultos: os processos de reconhecimento, validação e certificação de competências (RVCC), desenvolvidos nos Centros Novas Oportunidades (CNO), integrados no paradigma da aprendizagem ao longo da vida. Um dos exemplos do investimento estatal neste setor correspondeu ao Programa/Iniciativa Novas Oportunidades (2005-2012), promovido pelo Ministério da Educação e também pelo Ministério do Trabalho e da Solidariedade Social, tendo sido este um símbolo do investimento governamental, da altura, na qualificação. A União Europeia e a construção do Espaço Europeu de Educação influenciou e marcou a agenda política do programa Novas oportunidades. Nesta comunicação, pretendemos refletir sobre as representações dos atores dos CNO no que diz respeito ao impacto que os mesmos sentiam na sua ação das diretrizes emanadas pela União Europeia tendo em conta uma investigação realizada num CNO do distrito de Braga, Portugal. A investigação decorreu nos anos civis 2010 e 2011 e contemplou as seguintes metodologias: a) um estudo de caso: entrevistas à equipa técnica do CNO (formadores e técnicos de RVCC), b) a aplicação de um inquérito por questionário aos diretores/coordenadores dos CNO do Norte de Portugal (NUT III) (com uma amostra de 79,7\%, n=55). Os dados obtidos na investigação denunciam a influência dos processos de globalização no contexto local, confirmando a existência de um determinado grau de porosidade, neste programa educativo, das normas e diretrizes da União Europeia, sendo que, para os atores inquiridos, a política de educação/formação da União Europeia exerce demasiada influência sobre as políticas educativas nacionais. $\mathrm{O}$ aumento da qualificação dos portugueses, através do Programa Novas Oportunidades, colocou Portugal numa posição mais prestigiante no ranking dos países que contribuem para a construção do espaço europeu de educação. Assim sendo, o estudo das dinâmicas de educação de adultos locais de então ser entendido num contexto mais amplo da construção do espaço europeu de educação e de globalização.
\end{abstract}

Palabras clave: Educação de adultos, União Europeia, globalização

\section{Introdução}

No despertar do novo século esboçou-se em Portugal uma nova arquitetura na promoção do direito à educação destinada aos adultos: os processos de reconhecimento, validação e certificação de competências (RVCC), desenvolvidos nos Centros Novas Oportunidades (CNO), integrados no paradigma da aprendizagem ao longo da vida. Um dos exemplos do investimento estatal neste setor correspondeu ao Programa/Iniciativa Novas
Oportunidades (2005-2012), promovido pelo Ministério da Educação e também pelo Ministério do Trabalho e da Solidariedade Social, tendo sido este um símbolo do investimento governamental, da altura, na qualificação. A União Europeia e a construção do Espaço Europeu de Educação influenciou e marcou a agenda política do programa Novas oportunidades. Nesta comunicação, pretendemos refletir sobre as representações dos atores dos CNO no que diz respeito ao impacto que os mesmos sentiam na sua ação das diretrizes emanadas pela União Europeia tendo em conta uma investigação realizada num CNO do distrito de Braga, Portugal. A investigação decorreu nos anos civis 2010 e 2011 e contemplou as seguintes metodologias: a) um estudo de caso: entrevistas à equipa técnica do CNO (formadores e técnicos de RVCC), b) a aplicação de um inquérito por questionário aos diretores/coordenadores dos CNO do Norte de Portugal (NUT III) (com uma amostra de $79,7 \%, n=55)$.

\section{Efeitos das políticas da União Europeia em Portugal: o processo de RVCC do Programa Novas Oportunidades (2005-2012)}

As influências exercidas sobre a educação de adultos são cada vez mais diversificadas, sendo subsidiárias sobretudo do fenómeno da globalização. A pertinência do estudo sobre o impacto das políticas comunitárias em Portugal é cada vez mais importante para compreendermos as metamorfoses das políticas adotadas, nomeadamente no campo da educação numa era marcada pela globalização. A educação de adultos é um objeto de investigação que tem sido intercetado, ao longo dos tempos, por diferentes dimensões, quer situados no âmbito da educação formal, quer alocadas no âmbito da educação não formal e informal e sujeito a uma multiplicidade de pressões. O Programa Novas Oportunidades simboliza um exemplo claro das influencias e pressões da União Europeia sobre as políticas educativas portuguesas.

O programa Novas Oportunidades, através do processo de RVCC figurou, para muitos portugueses, uma possibilidade de aumentarem as suas qualificações, tanto para nível básico como secundário.

A identificação dos jogos de influência da União Europeia, nomeadamente das normas e diretrizes na acção concreta dos atores locais, em particular, na gestão dos CNO representou uma das dimensões da investigação encetada. No inquérito que aplicamos aos diretores/coordenadores dos CNO do NUT III, pretendíamos conhecer as representações dos diretores/coordenadores relativamente ao impacto que os 
mesmos sentiam relativamente às diretrizes emanadas pela União Europeia e que repercussões essas mesmas normas poderiam vir a ter no âmbito dos processos de RVCC.

Numa primeira instância pretendíamos conhecer se os diretores/coordenadores identificavam, de facto, algum tipo de interferência das políticas educativas da União Europeia, sobretudo através dos programas de financiamento do Fundo Social Europeu (FSE) no desenvolvimento da ação pelos profissionais do CNO. Os dados obtidos no inquérito denunciam que as normas do FSE condicionam a aç̧ão do CNO, sendo que 45,5\% dos diretores/coordenadores concordam com esta hipótese e 23,6\% concordam totalmente. Apenas 14,5\% discordam desta afirmação e 16,4\% revelaram não ter opinião formada sobre este impacto, conforme os dados da seguinte figura:

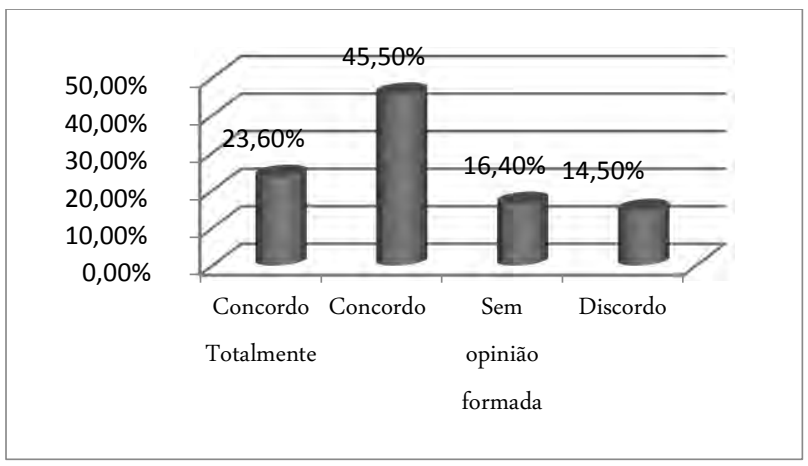

Figura 1. As normas do Fundo Social Europeu condicionam a ação do CNO

Decorrente dos condicionalismos desvendados nos dados presentes no gráfico acima, consideramos importante conhecer a opinião dos diretores/coordenadores dos CNO sobre o grau de interferência que as políticas educativas / formação da União Europeia poderiam exercer sobre as políticas educativas nacionais. As convicções dos inquiridos direcionam-se maioritariamente para a conceção de que as políticas da União Europeia influenciam demasiado as políticas educativas nacionais, sendo que $54,5 \%$ concordam e 10,9\% concordam totalmente com esta ideia. Contudo, 20\% dos inquiridos revelou não ter opinião formada sobre este assunto e 14,5\% discordaram deste pendor excessivo das políticas da União Europeia sobre as políticas educativas nacionais.

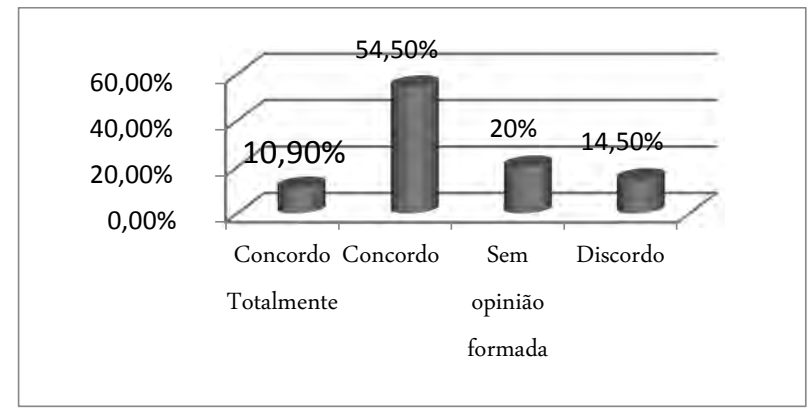

Figura 2. As políticas de Educação / Formação da União Europeia influenciam demasiado as políticas educativas nacionais
Esta influência deve também ser analisada tendo em consideração outras variáveis, nomeadamente o financiamento, o fornecimento e a regulação do PNO. Tendo como inspiração o trabalho desenvolvido por R. Dale (2008) e F. Antunes (2001:177), podemos, à semelhança do que a autora considera no âmbito das escolas profissionais, analisar as três variáveis no contexto do PNO. No âmbito do financiamento, devemos ter em consideração que este programa se define pelo seu carácter público e estatal, sem qualquer tipo de custos para os adultos. Todavia, e no seio do financiamento do PNO, devemos registar o elevado patrocinio por parte dos fundos estruturais da União Europeia e do Estado Português.

Este financiamento é concretizado através de candidaturas a programas específicos da União Europeia, como o POPH e garante a sobrevivência não só da formação nestes contextos organizacionais como também, em muitos casos, da organização em si. Neste financiamento, o Estado reformula o seu papel, como explicam L. Lima, P. Guimarães \& R. Oliveira (2007, 43): "Esta opção surge como resultado de políticas sociais e educativas que sugerem a subtracção de certas responsabilidades ao Estado. Deste modo, são multiplicadas as responsabilidades destas organizações, através de transferências de quantias cada vez mais avultadas, acrescentando objectivos e formas de intervir nas comunidades que nem sempre são articuláveis com as suas finalidades”.

O fornecimento deste programa é proporcionado por diversas entidades de natureza diversificada: pública, privada e terceiro sector ${ }^{1}$, sendo que, dentro de cada natureza, vários tipos de organização assumem esta função: escolas públicas, escolas privadas, escolas profissionais, empresas, associações de desenvolvimento local, etc. Como explicita a Portaria $n^{\circ}$ 379/2008, de 21 de Maio: "Os Centros Novas Oportunidades podem ser criados por entidades públicas ou privadas, adiante designadas por entidades promotoras, designadamente estabelecimentos de ensino, centros de formação profissional, autarquias, empresas e associações, com significativa expressão territorial ou sectorial e capacidade técnica instalada, em função sobretudo dos sectores e públicos a que se dirigem"(Artigo III, I).

Portanto, a natureza das organizações é plural, combinando vários tipos de organizações quer escolares quer de natureza empresarial, associativa, entre outras. Esta diversidade de entidades promotoras do RVCC leva-nos a considerar que, apesar de nos encontrarmos em presença de um programa estatal, no entanto, a execução do mesmo é partilhada por diferentes atores da sociedade civil. Esta situação pode ser interpretada tendo em conta o pensamento de F. Rodrigues \& S. Stoer

${ }^{1}$ Sobre os diferentes contextos, L. Lima \& A. Afonso $(2006,211)$ referem: "Em Portugal, a progressiva erosão do papel do Estado e das políticas públicas no âmbito da educação popular de adultos, que ocorreu de forma mais visível a partir de meados da década de 1980, foi correlativa dos apelos à sociedade civil por parte dos diversos governos, e do protagonismo da lógica da qualificação e da gestão de recursos humanos, com especial incidência no ensino recorrente de adultos e na formação profissional (cf. Lima, 2005)". 
(1998,95-96) quando abordam que o contexto português assenta na "tradição de um estado centralizador apesar de (e talvez por isso mesmo) uma fraca provisão social", mas "coexistindo uma 'sociedade providencia' sobretudo baseada em redes de microssolidariedades de natureza mais ou menos informal”. Inerente à construção do Estado de bem estar social, até hoje inacabado, a "integração de Portugal em espaço de União Europeia foi factor de reforço, senão mesmo de imposição, de iniciativas de orientação plurissectorial e pluriparceiros" (idem, ibidem). Neste contexto, muitas das medidas associadas a programas europeus "pautam-se por critérios de institucionalização de partenariados, tomando, quase sempre, a forma de projectos" (idem, ibidem).

Contudo, apesar desta diversidade organizacional, a implementação do PNO, no seio destas organizações pode estar sujeito aos ditames deste programa, que é alimentado por financiamentos externos às organizações. Neste âmbito,"a capacidade de intervenção das organizações pode estar comprometida, de resto porque elas assumem funções que resultam frequentemente de processos de privatização de serviços antes assumidos pelo Estado" (Lima, Guimarães \& Oliveira, 2007, 42).

A regulação do programa Novas Oportunidades é essencialmente estatal, protagonizada pela ANQ, centralizando a definição dos programas, do referencial de competências-chave e de todas as orientações técnico-pedagógicas e financeiras. O controlo é executado não só a partir da execução das metas como também a partir dos programas informáticos (SIGO e SIIFSE). Ao CNO é cometido a gestão pedagógica e financeira encontrando-se toda a direção situada fora dos CNO. Assim, seguimos a linha de pensamento de L. Lima, P. Guimarães e R. Oliveira $(2007,45)$ quando referem que“uma política pública apenas assente em processos de candidatura e de contratualizaçao parece ignorar as aludidas dificuldades e, sobretudo, centra-se mais na selecção de potenciais parceiros e no controlo das suas acções, do que na promoção das condições educacionais e organizacionais indispensáveis à realização de uma política pública assente na acção de organizações não governamentais prestadoras de serviços".

Embora a execução do PNO esteja a cargo de uma multiplicidade de organizações, a lógica de candidatura aos financiamentos acaba por controlar e transformar a ação dos atores organizacionais, numa reprodução de carácter eminentemente técnico.

No seguinte quadro clarificamos os seguintes indicadores:

\begin{tabular}{|l|l|}
\hline Financiamento & Estado/União Europeia \\
\hline Fornecimento & $\begin{array}{l}\text { Plural: Escolas, Associações, } \\
\text { Empresas/Setor Público, Privado, } \\
\text { Terceiro Sector }\end{array}$ \\
\hline Regulação & $\begin{array}{l}\text { União Europeia, Estado (ANQ); } \\
\text { CNO (apenas gestão) }\end{array}$ \\
\hline
\end{tabular}

Quadro n. ${ }^{\circ}$ 1. Governação do Programa Novas Oportunidades
Neste cenário, podemos concluir que a governação do PNO assenta numa política ambígua e híbrida que coloca o Estado como ator principal no financiamento e na regulação mas acompanhado por outros protagonistas no fornecimento, cuja natureza é diversificada. Nesta linha de pensamento, "o lançamento do dispositivo de RVCC envolveu um arranjo institucional para a coordenação das atividades (governação) que pode ser sumariamente descrito nos seguintes termos: o financiamento é público, nacional e da UE; o fornecimento e a propriedade são assumidos por entidades públicas, privadas lucrativas, solidarias e comunitárias, de escala nacional e subnacional; a regulação e protagonizada pela UE, o Estado nacional e os fornecedores. A coordenação destas atividades envolve formas institucionais características da burocracia estatal e do (quase - ) mercado, eventualmente combinadas, em certas circunstancias, com elementos derivados do terceiro sector/comunidade" (Antunes, 2011,21).

Após a corroboração dos condicionalismos da União Europeia face às políticas educativas nacionais e à ação protagonizada pelos diferentes atores no CNO, era importante analisar se as normas provindas deste contexto internacional tinham em conta as especificidades da política educativa portuguesa, as idiossincrasias dos contextos e dos atores locais. Foi neste intuito que questionamos os diretores/coordenadores dos CNO no sentido de nos indicarem o seu grau de concordância relativamente à eventual harmonia entre as normas da União Europeias e as especificidades do contexto português. Os dados revelam que quase metade dos inquiridos discorda $(47,3 \%)$ da ideia de que as normas da União Europeia sejam adequadas à realidade portuguesa. É, contudo, de ressalvar que $40 \%$ dos diretores/coordenadores não têm opinião formada sobre este item. Todavia, uma percentagem residual de $12,7 \%$ concordam que as normas da União Europeia são adequadas à realidade portuguesa, conforme se encontra expresso na Figura 3.

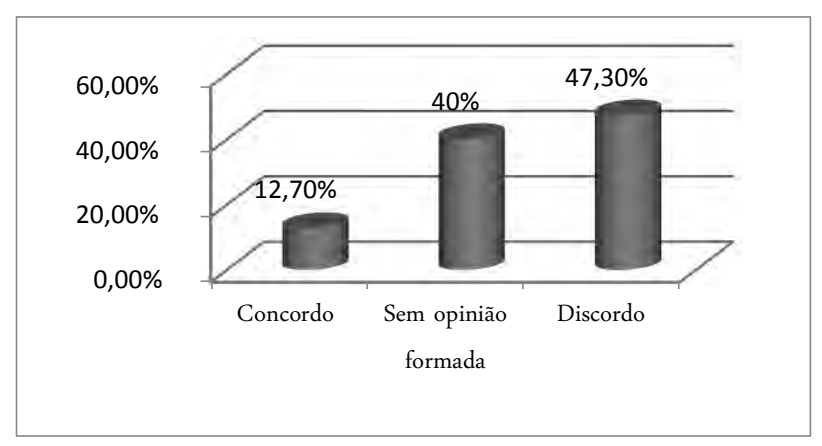

Figura 3. As normas da União Europeia são adequadas à realidade portuguesa

Tendo em conta a integração de Portugal no contexto da União Europeia e o consequente acesso a programas de financiamento da mesma, tornava-se importante perceber até que ponto os atores locais consideravam a relação entre o binómio metas dos CNO e União Europeia como uma conexão importante. Neste sentido, os diretores/coordenadores demonstraram 
maioritáriamente que a existência das metas definidas pela ANQ no âmbito do Programa Novas Oportunidades é importante para o cumprimento dos objetivos da União Europeia (52,7\% e 7,3\% concordaram e concordaram totalmente). Cerca de $20 \%$ e $3,6 \%$ dos inquiridos discordaram e discordaram totalmente respetivamente desta conceção, conforme pode ser visualizado no gráfico $n^{\circ} 4$.

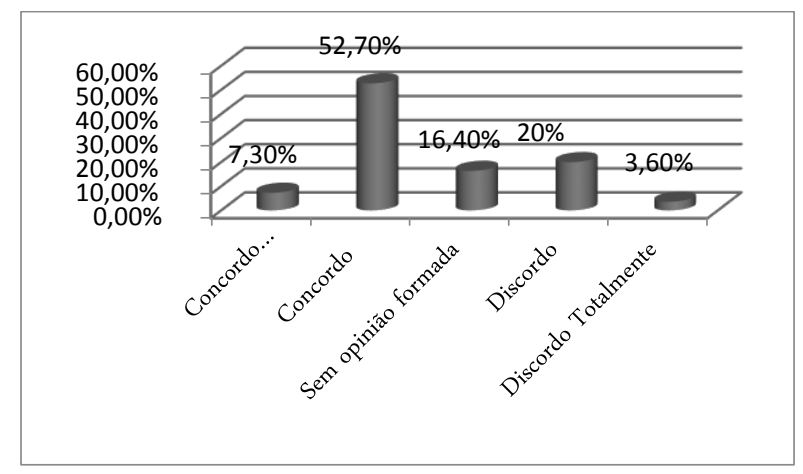

Figura 4. As metas definidas pela ANQ são importantes para o cumprimento dos objectivos da União Europeia

A importância das metas na concretização do PNO é reforçada no âmbito da posição de Portugal no contexto europeu e internacional, dado o cariz eminentemente económico associado à qualificação, como se deduz da afirmação prioritária de objectivos no apoio ao crescimento económico e do emprego do governo de José Sócrates, conforme explicita o discurso do Ministro dos Assuntos Parlamentares, da época, Augusto Santos Silva:"Do ponto de vista do Governo, para garantir a batalha do crescimento da economia e do crescimento do emprego, é preciso agir em cinco frentes:[...] quinta, esforço público e público-privado na promoção da qualificação, seja a qualificação e a aprendizagem dos jovens em idade escolar, seja a da população activa e na dupla vertente da sua certificação escolar e da sua certificação profissional. Ora, esta política económica está em linha com o melhor benchmarking da União Europeia, goza do apoio deste Parlamento e de outras instituições do Estado, das nossas elites económicas, empresariais e sociais e conta com o apoio da generalidade da opinião pública"(Diário da Assembleia da República, Reunião Plenária de 22-6-2006, n. ${ }^{\circ} 138$, de 23-6-2006: 6316-6317, negrito nosso).

$\mathrm{Na}$ linha dos dados obtidos no inquérito aos diretores/coordenadores, uma das entrevistadas do estudo de caso reconheceu a influência das políticas da União Europeia no âmbito do PNO, nomeadamente a determinação das elevadas metas que os CNO têm de alcançar. Nas suas palavras: "isto surgiu como a ideia de nos colocar ao nível europeu, em qualificações, o mais próximo possível. A nível de escolaridade obrigatória, era uma desgraça. A ideia foi facilitar e ajudar. Concordo porque temos aqui pessoas que, realmente, têm competências ao $9^{\circ}$ ano, mas concordo que este processo deveria ser apenas um processo de reconhecimento de competências, ou seja, as pessoas não deveriam precisar de tanta formação complementar, não deveriam precisar tanto de formação modular para conseguir atingir. Para isso, teriam que ir para os cursos EFA, que também fazem parte das Novas Oportunidades" (excerto da entrevista $\mathrm{n}^{\circ} 7$ ).

Assim sendo, embora não tenhamos dados que nos permitam aferir o grau de intensidade da porosidade que o PNO revela na absorção dos processos de globalização/europeização, os dados permitem-nos, contudo, partilhar da opinião de C. Estêvão (2009:41) quando considera que:"a globalização tem vindo a impor um novo mandato aos diferentes países no sentido de, em nome das vantagens competitivas que podem alcançar, terem de redefinir os seus sistemas de ensino e de formação nacionais em termos de qualidade, avaliada segundo padrões internacionais. Isto exige que os sistemas educacionais se rendam à cultura da performatividade sistémica, através da imposição de indicadores de desempenho como os novos mecanismos de ligação entre o centro que produz a política e as periferias que a põem em prática”.

Neste contexto, reforçamos que a urgência do aumento da elevação das taxas de qualificação dos portugueses; a definição e a construção de um amplo mecanismo de controlo a partir de metas e a administração altamente centralizada que o programa Novas Oportunidades espelham uma clara divisão entre os concetores de uma política/programa (ANQ) e os executores (CNO). Do mesmo modo, estas condicionantes levantam outras interrogações sobre o processo, nomeadamente, e na linha de pensamento de R. Barros (2011:162) questiona-se se "as respostas encontradas atualmente nos contextos de práticas de RVCC não dão azo a uma profunda deturpação de uma modalidade educativa realizada com adultos que se deveria caracterizar devido à sua essência critica da sua própria génese, por um 'modo de trabalho apropriativo' (cf. Lesne, 1984) assente na real possibilidade de explorar uma relação pedagógica de tipo mais horizontal e, portante, mais problematizador e emancipatório. Ou seja, uma modalidade promissora que afinal as condicionantes impostas centralmente, por Lisboa e por Bruxelas, mais não parecem fazer atualmente do que cooptar, de modo indireto e subtil (numa agenda oculta?), mas de tal modo eficaz e eficiente".

Em suma, podemos considerar o pendor centralizador por parte do Estado sobre as organizações que desenvolvem o PNO, de modo a responder aos desafios supranacionais e ao cumprimento de benchmarks, definidas no âmbito da construção de um projeto europeu do Espaço Europeu de Educação.

\section{Conclusão}

O aumento da qualificação dos portugueses, através do Programa Novas Oportunidades, coloca Portugal numa posição mais prestigiante no ranking dos países que contribuem para a construção do espaço europeu de educação. O PNO, integrado no âmbito da aprendizagem ao longo da vida, sinaliza as pressões do Estado, da União Europeia e do mercado de aprendizagem. A 
política de educação/formação da União Europeia, na opinião dos diretores/coordenadores inquiridos, exerce demasiada influência sobre as políticas educativas nacionais, ainda que a maioria dos atores discorde do facto de as mesmas serem adequadas à realidade portuguesa. De igual modo, os atores também consideraram que as normas do Fundo Social Europeu condicionam a ação do CNO e reconhecem que as metas definidas pela ANQ são importantes para o cumprimento dos objetivos da União Europeia. Deste modo, sublinha-se a influência dos processos de globalização no contexto local, confirmando a existência de um determinado grau de porosidade, neste programa educativo, das normas e diretrizes da União Europeia. O estudo das dinâmicas de educação de adultos locais de então ser entendido num contexto mais amplo da construção do espaço europeu de educação e de globalização.

\section{Referências}

ANTUNES, Fátima (2001). "Os locais das escolas profissionais: Novos papéis para o Estado e a europeização das políticas educativas"; in Stoer, Stephen R.; Cortesão, Luiza \& Correia, José A. (orgs.). Transnacionalização da educação - Da crise da Educação à 'Educação' da Crise. Porto: Edições Afrontamento, pp. 163-210.

ANTUNES, Fátima (2011). "Governação, reforma do Estado e políticas de educação de adultos em Portugal: Pressões globais e especificidades nacionais, tensões e ambivalências"; in Revista Crítica de Ciências Sociais, 92, pp. 3-29.

BARROS, Rosanna (2011). A Criação do Reconhecimento de Adquiridos Experienciais (RVCC) em Portugal - Uma Etnografia Crítica em Educação de Adultos. Chiado Editora.
DALE, Roger. (2001) "Globalização e educação: demonstrando a existência de uma "cultura educacional mundial comum' ou localizando uma 'agenda globalmente estruturada para a educação'?”. Educação, Sociedade, \& Cultura, n. ${ }^{\circ} 16,1$, pp. 133-169.

DALE, Roger (2008). "Construir a Europa através de um Espaço Europeu de Educação"; in Revista Lusófona de Educação, n. ${ }^{\circ} 11$, pp. 13-30.

ESTÊVÃO, Carlos (2009). "Educação, globalizações e cosmopolitismos: novos direitos, novas desigualdades"; in Revista Portuguesa de Educação, 22(2), pp. 35-52.

LIMA, Licínio \& AFONSO, Almerindo (2006). "Políticas públicas, novos contextos e actores em educação de adultos"; in Lima, Licínio C. (Org.), Educação Não Escolar de Adultos. Iniciativas em Contextos Associativos. Braga: Universidade do Minho/Unidade de Educação de Adultos, pp. 205-229.

LIMA, Licínio; GUIMARÃES, Paula; \& OLIVEIRA, Raquel (2007). "Organização Associativa e Produção Local de Políticas de Educação de Adultos"; in CASTRO, Rui Vieira (org.); LIMA, Licínio C.; DIONÍSIO, Maria Lourdes; GUIMARÃES, Paula; OLIVEIRA, Raquel \& SANCHO, Amélia Vitória. Contexto Organizacional, Orientações e Práticas de Educação de Adultos - Os Cursos EFA numa Associação Local. Vila Verde: ATAHCA/UEA-UM, pp. 15-44.

RODRIGUES, Fernanda \& STOER, Stephen. (1998). Entre Parceria e Partenariado. Oeiras: Celta.

\section{Legislação:}

Portaria n. ${ }^{\text {o } 379 / 2008, ~ d e ~} 21$ de maio

Diário da Assembleia da República, Reunião Plenária de 22-6-2006, n. ${ }^{\circ}$ 138, de 23-6-2006 